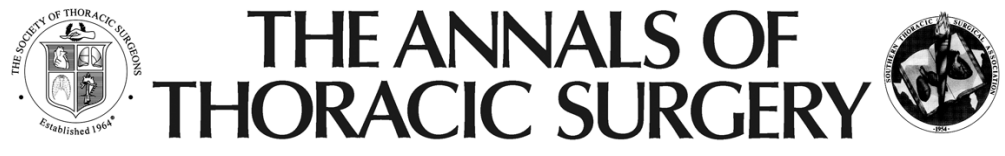

\author{
Flexible Videopericardioscopy in cT4 Nonsmall-Cell Lung Cancer With Radiologic \\ Evidence of Proximal Vascular Invasion \\ Eugenio Pompeo, Federico Tacconi and Tommaso C. Mineo \\ Ann Thorac Surg 2007;83:402-408 \\ DOI: 10.1016/j.athoracsur.2006.09.031
}

The online version of this article, along with updated information and services, is located on the World Wide Web at:

http://ats.ctsnetjournals.org/cgi/content/full/83/2/402

The Annals of Thoracic Surgery is the official journal of The Society of Thoracic Surgeons and the Southern Thoracic Surgical Association. Copyright (C) 2007 by The Society of Thoracic Surgeons. Print ISSN: 0003-4975; eISSN: 1552-6259. 


\title{
Flexible Videopericardioscopy in cT4 Nonsmall-Cell Lung Cancer With Radiologic Evidence of Proximal Vascular Invasion
}

\author{
Eugenio Pompeo, MD, Federico Tacconi, MD, and Tommaso C. Mineo, MD \\ Thoracic Surgery Division, Tor Vergata University School of Medicine, Rome, Italy
}

Background. The purpose of this study was to evaluate feasibility and effectiveness of flexible videopericardioscopy (FVP) in assessing resectability of cT4 nonsmall-cell lung cancer (NSCLC) with radiologic evidence of proximal vascular invasion.

Methods. Between March 2003 and December 2005, 22 patients with NSCLC deemed unresectable owing to signs of proximal vascular invasion at multislice computed tomography were included in a nonrandomized prospective study entailing FVP performed before curative-intent thoracotomy. Primary outocome measures were technical feasibility (graded from $1=$ poor to $3=$ excellent) and quality of anatomic visualization (graded as diagnostic or nondiagnostic). Patients with FVP evidence of proximal vascular invasion did not receive thoracotomy and were included in an induction chemoradiotherapy protocol.

Results. Mean operative time was $31 \pm 6$ minutes. Technical feasibility ranged from good to excellent in 21 patients. In 1 patient, FVP was not completed owing to

$\mathrm{P}^{\mathrm{a}}$ atients with nonsmall-cell lung cancer (NSCLC) showing radiologic evidence of proximal vascular invasion are classified within the stage IIIB [1] and conventionally considered unresectable. However, a 5-year survival rate of $18.2 \%$ to as high as $35.7 \%$ has been reported in this subgroup after surgical resection [2-6]. Unfortunately, imaging-based prediction of NSCLC resectability is not always accurate, particularly as far as neoplastic involvement of mediastinal structures and proximal pulmonary vessels is concerned [7-11]. Inaccurate preoperative staging increases the number of useless thoracotomies and incomplete resections and can even lead to denying surgical treatment to potentially resectable patients. Although video-assisted thoracoscopic surgery is now commonly employed as a NSCLC staging tool, its reliability in assessing proximal vascular involvement in cT4 lesions remains questionable [12]. Therefore, exploration of the pericardial cavity by rigid thoracoscope has been proposed by Loscertales and associates [13] as a more accurate staging tool in this setting.

Accepted for publication Sept 1, 2006.

Address correspondence to Dr Pompeo, Cattedra di Chirurgia Toracica, Policlinico Tor Vergata, V. le Oxford 81, Rome 00133, Italy; e-mail: pompeo@med.uniroma2.it. intrapericardial adhesions. In 7 patients, FVP disclosed no tumor spread to intrapericardial pulmonary vessels, and radical resection was carried out. The FVP findings were considered not diagnostic because of poor visualization of the right pulmonary artery in 2 patients with bulky hilar tumors. There was no operative mortality and morbidity. Mean hospital stay was $2.9 \pm 1$ days for patients who did not undergo thoracotomy and $6.3 \pm 1$ days for patients receiving FVP plus resection. Definitive pathologic staging in patients undergoing resection was pT3N1 $(n=2)$, pT3N0 $(n=2)$, TT2N0 $(n=3)$, and pT2N1 ( $\mathrm{n}=1)$.

Conclusions. Flexible videopericardioscopy proved safely feasible and allowed a better assessment of centrally located NSCLC, with radiologic evidence of proximal vascular involvement eventually resulting in increased resectability rate.

(Ann Thorac Surg 2007;83:402-8)

(C) 2007 by The Society of Thoracic Surgeons

We have undertaken a prospective nonrandomized study aimed at evaluating the usefulness of pericardioscopy performed by a flexible videobronchoscope during exploratory video-assisted thoracoscopic surgery, namely, flexible videopericardioscopy (FVP), for patients with centrally located NSCLC who were considered unresectable owing to radiologic evidence of proximal vascular involvement.

\section{Material and Methods}

The study cohort entailed 22 patients, 17 men and 5 women with a mean age $64 \pm 7$ years, with centrally located NSCLC referred to our institution between March 2003 and December 2005. The study was approved by the Ethics Commettee of the Tor Vergata University, and written informed consent to the study and the surgical procedure was obtained from each patient.

Eligibility criteria included a diagnosis of NSCLC; good performance status (Karnofsky score $>90$ ); no medical, functional, or bronchoscopic contraindication to pneumonectomy; and clinical stage IIIB with multislice computed tomography (CT) evidence of proximal vascular invasion according to previously validated criteria $[7,8]$, 

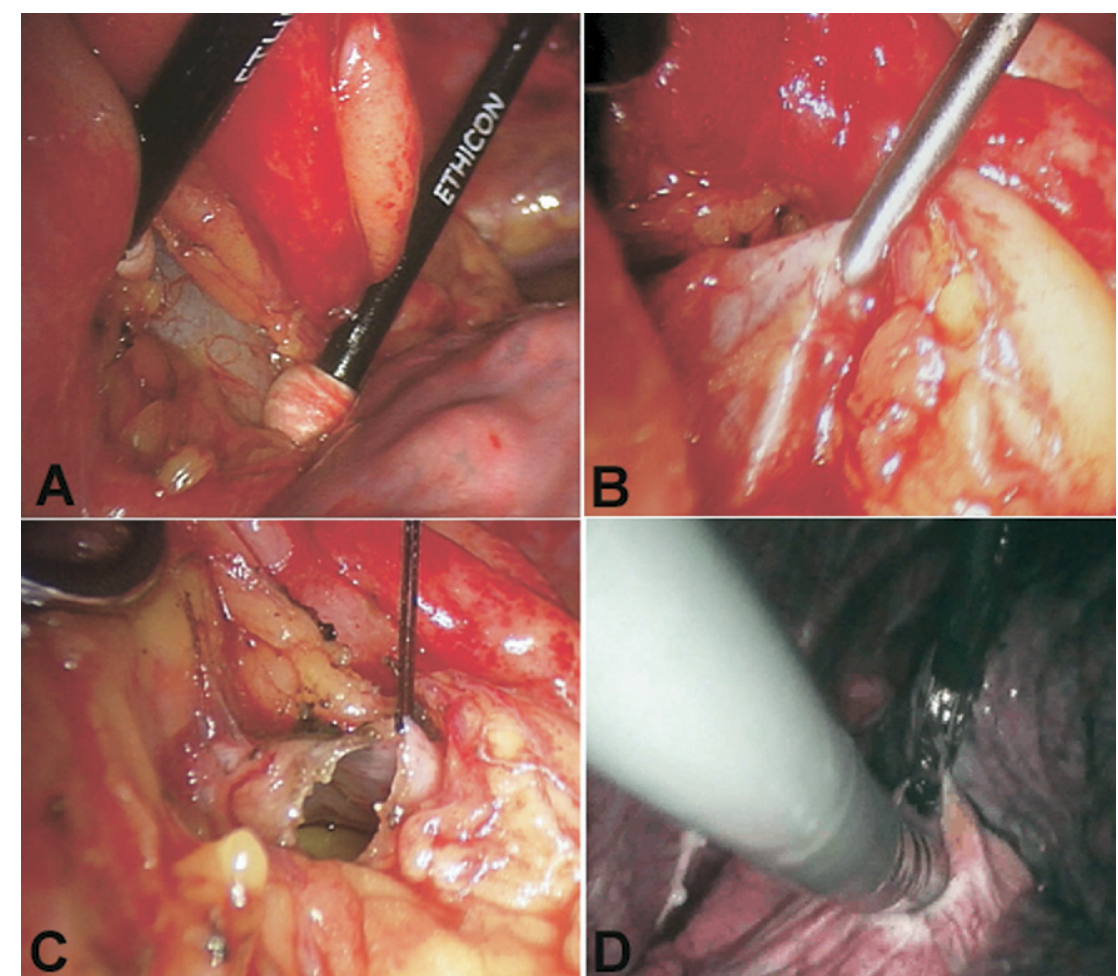

Fig 1. (A) After blunt dissection, (B) the fibrous pericardium is grasped and opened for about $2 \mathrm{~cm}$; (C) 3-0 silk sutures widen the pericardial opening. (D) The fiberoptic videobronchoscope is inserted into the pericardial cavity for exploration.

including (1) contact between a pulmonary vessel and the tumoral mass for more than $3 \mathrm{~cm}$ or more than 90 degrees, or both, without a recognizable fat plane, (2) distortion or indentation of the involved vessels, or (3) obliteration of pulmonary vessel lumen.

Exclusion criteria included malignant pleural effusion, imaging-based suspicion of vertebral or esophageal involvement, histologically proven N2-3 disease, M1 disease, previous induction therapy, previous FVP, and cardiac surgery or thoracic surgery on the side targeted for FVP.

In 15 patients, histologic diagnosis was obtained preoperatively through fiberoptic bronchoscopy $(n=9)$ or CT-guided core-needle biopsy $(n=6)$. In the remaining patients, biopsy specimens were obtained during videoassisted thoracoscopic surgery.

\section{Study Design}

The study was set as a prospective nonrandomized clinical investigation. The primary outcome measure was quality of anatomic visualization, which was scored as diagnostic or nondiagnostic on the basis of the possibility to provide accurate real-time assessment of the tumor local extension. In particular, anatomic visualization was defined by intraoperative assessment of three subjective indexes by two surgeons (T.C.M., E.P.): (1) pulmonary vessel recognition; (2) tumor-tissue discernment; and (3) estimation of tumor-free proximal vessels portion.

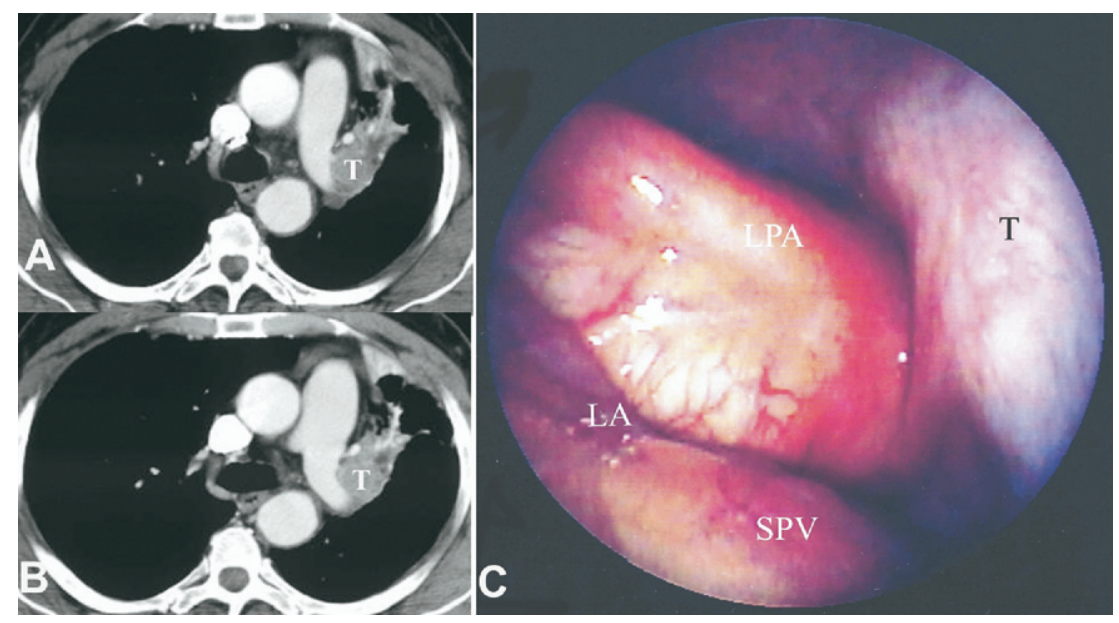

Fig 2. (A, B) Axial computed tomography scan images showing proximal tumor involvement of the left pulmonary artery in patient 8 . (C) Flexible videopericardioscopy (FVP) in the same patient showed absent tumor spread to the intrapericardial tract of pulmonary artery, which is confirmed at thoracotomy when pneumonectomy will be performed. (LA = left atrium; $L P A=$ left pulmonary artery; $S P V=$ superior pulmonary vein; $T=$ tumor.) 
Whenever all three indexes were judged satisfactorily assessed by both surgeons, the result was scored as diagnostic, whereas if at least one of the three indexes was considered inadequately assessed or consensus was not reached, the result was scored as nondiagnostic.

The sample size of 22 patients was calculated assuming achieving an adequate anatomic visualization in at least $80 \%$ of patients with a lower confidence interval of more than $60 \%$ and expecting to improve resectability rate and reduce exploratory thoracotomies. An interim analysis was performed after treatment of the first 10 patients to rule out achievement of resectability through FVP in at least 3 patients.

Complete preoperative clinical staging was performed, including total body positron emission tomography scan using fluorodeoxyglucose (FDG-PET) integrated with multislice CT and fiberoptic bronchoscopy.

Patients in whom FVP indicated a resectable disease immediately proceeded to thoracotomy during the same surgical session. Patients with findings suggestive of unresectable disease at FVP did not proceed to thoracotomy and underwent neoadjuvant chemoradiotherapy. Finally, patients in whom FVP was not feasible or nondiagnostic were asked to choose between exploratory thoracotomy or neoadjuvant chemoradiotherapy.

For the study's purpose, we defined as unresectable a tumor mass extending to the intrapericardial tract of pulmonary vessels with a tumor-free portion of less than $1 \mathrm{~cm}$ for pulmonary veins and of less than $2 \mathrm{~cm}$ for pulmonary artery.

\section{Radiologic Assessment}

Computed tomography assessment was performed using a multidetector row helical scanner (LightSpeed 16; General Electric, Milwaukee, Wisconsin), with a singlebreath-holding technique. Iodinated contrast medium was administred at a rate of $3.0 \mathrm{~mL} / \mathrm{s}$ to a total dose of $120 \mathrm{~mL}$ (Optiray 300; Tyco Healthcare, Mansfield, MA). Collimation of $1.0 \mathrm{~mm}$ was used, with a pitch of $6.0 \mathrm{~mm}$. Data acquisition started $40 \mathrm{~s}$ after beginning the injection. Total scanning time was $32 \mathrm{~s}$, according to the protocol by Padhani and coworkers [14]. Images were finally processed in a dedicated workstation system for threedimensional and multiplanar reconstructions. The thoracic surgeon and the radiologist both evaluated the quality of each CT slice; consensus was required for inclusion in the study.

\section{Surgical Technique}

Flexible videopericardioscopy was performed under general anesthesia with double-lumen tube intubation and single-lung ventilation. The patient was positioned leaning 45 degrees. A first trocar was inserted in the sixth intercostal space, on the midaxillary line. After verified absence of pleural adhesions, two additional trocars were placed in the fifth and fourth intecostal spaces on the anterior axillary line. Exploration of the entire pleural cavity, lung, and mediastinum was accomplished firstly. Next, a pinhole incision was performed with hook and electrocautery on the fibrous pericardium about $1 \mathrm{~cm}$ anterior to the phrenic nerve. The incision was then enlarged with endoscopic shears to allow insertion of the videobronchoscope (Fig 1), and 3-0 silk sutures were passed endoscopically on both margins of the pericardiotomy, to apply traction and widen the intrapericardial space during FVP. Accurate exploration of all vascular elements within the pericardium was then accomplished, with particular attention to the vessels suspected of tumor involvement on the basis of multislice CT findings.

On the right side, FVP enabled exploration of both the superior and inferior pulmonary veins, while the pulmonary artery was visualized between the superior vena cava and superior pulmonary vein, above Allison's sinus. On the left side, both pulmonary veins were explorable while the main pulmonary artery was widely explored up to its origin from the common trunk (Fig 2). To minimize the risk of vascular injury, we did not obtain biopsies to confirm neoplastic involvement. After completion of the procedure, the pericardial opening was not sutured. Next, patients with resectable disease were placed in full lateral decubitus position and underwent thoracotomy in the same surgical session whereas patients showing proximal vascular invasion suggesting unresectable disease were enrolled in a neoadjuvant chemotherapy protocol.

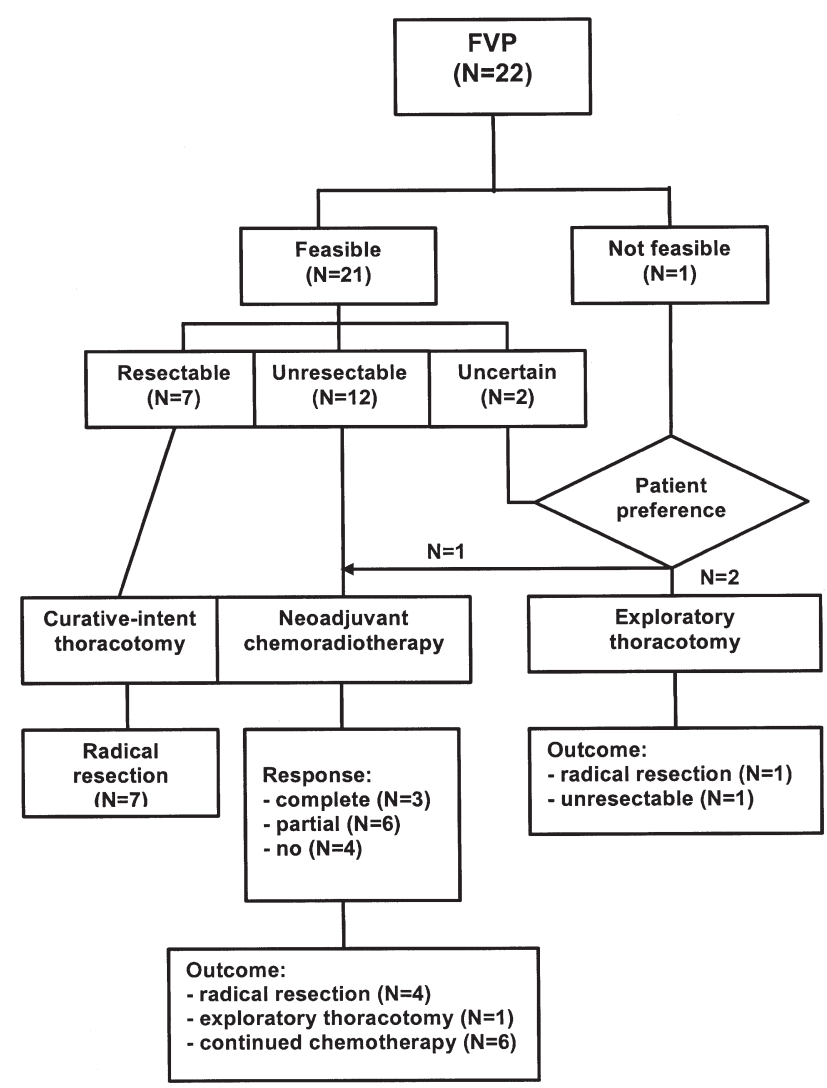

Fig 3. Outcome of the study cohort. (FVP = flexible videopericardioscopy.) 
Table 1. Main Findings of the Entire Series

\begin{tabular}{|c|c|c|c|c|c|c|c|c|}
\hline Case & $\begin{array}{l}\text { Age } \\
\text { (Years) }\end{array}$ & Side & Histology & $\begin{array}{l}\text { Involved } \\
\text { Vessels }\end{array}$ & $\begin{array}{c}\mathrm{CT} \\
\text { Finding }\end{array}$ & $\begin{array}{c}\text { Tumor Spread } \\
\text { at FVP }\end{array}$ & Treatment & Outcome \\
\hline 1 & 55 & Right & Squamous & PA & 1 & Present & $\begin{array}{l}\text { Induction CRT }+ \\
\text { upper lobectomy }\end{array}$ & Dead 22 months \\
\hline 2 & 66 & Left & Adeno & PA & $1-3$ & Absent & $\begin{array}{l}\text { Upper lobectomy }+ \\
\text { arterial patch }\end{array}$ & Alive 40 months \\
\hline 3 & 76 & Right & Large cell & LA & 1,2 & Absent & $\begin{array}{l}\text { Pneumonectomy }+ \text { LA } \\
\text { resection }\end{array}$ & Dead 2 months \\
\hline 4 & 56 & Left & Large cell & IPV & 1,2 & Present & Induction CRT & Dead 1 month \\
\hline 5 & 67 & Right & Squamous & PA & 1,2 & Undetermined & $\begin{array}{l}\text { Exploratory } \\
\text { thoracotomy }+ \text { CRT }\end{array}$ & Dead 15 months \\
\hline 6 & 69 & Left & Adeno & SPV & 2 & Present & $\begin{array}{c}\text { Induction CRT + } \\
\text { definitive CRT }\end{array}$ & Dead 25 months \\
\hline 7 & 72 & Left & Squamous & IPV & 2 & Present & $\begin{array}{l}\text { Induction CRT + } \\
\text { lower lobectomy }\end{array}$ & Alive 35 months \\
\hline 8 & 53 & Left & Large cell & PA & 1,2 & Absent & Pneumonectomy & Alive 31 months \\
\hline 9 & 66 & Right & Adeno & $\mathrm{SPV}+\mathrm{SVC}$ & $1-3$ & Present & $\begin{array}{l}\text { Induction CRT + } \\
\text { pneumonectomy }\end{array}$ & Alive 29 months \\
\hline 10 & 59 & Left & Squamous & LA & $1-3$ & Present & $\begin{array}{c}\text { Induction CRT }+ \\
\text { definitive CRT }\end{array}$ & Dead 18 months \\
\hline 11 & 55 & Left & Adeno & PA & $1-3$ & Absent & Pneumonectomy & Dead 23 months \\
\hline 12 & 67 & Left & Adeno & LA & $1-3$ & Not feasible & $\begin{array}{l}\text { Pneumonectomy }+ \text { LA } \\
\text { resection }\end{array}$ & Alive 25 months \\
\hline 13 & 69 & Left & Squamous & IPV & 1,2 & Present & $\begin{array}{l}\text { Induction CRT + } \\
\text { pneumonectomy }\end{array}$ & Alive 21 months \\
\hline 14 & 67 & Right & Large cell & SPV & $1-3$ & Present & Induction CRT & Dead 3 months \\
\hline 15 & 55 & Right & Adeno & PA & 2 & Absent & $\begin{array}{l}\text { Upper lobectomy }+ \\
\text { arterial patch }\end{array}$ & Alive 16 months \\
\hline 16 & 69 & Left & Adeno & IPV & 1,2 & Present & $\begin{array}{c}\text { Induction CRT + } \\
\text { definitive CRT }\end{array}$ & Alive 17 months \\
\hline 17 & 72 & Left & Squamous & $\mathrm{PA}+\mathrm{Ao}$ & 1,2 & Present & $\begin{array}{l}\text { Induction CRT + } \\
\text { exploratory } \\
\text { thoracotomy + CRT }\end{array}$ & Alive 16 months \\
\hline 18 & 69 & Right & Adeno & SPV & 1,2 & Absent & Pneumonectomy & Alive 14 months \\
\hline 19 & 70 & Right & Adeno & PA & 2 & Undetermined & $\begin{array}{c}\text { Induction CRT + } \\
\text { definitive CRT }\end{array}$ & Dead 6 months \\
\hline 20 & 58 & Left & Adeno & LA & 1 & Absent & $\begin{array}{l}\text { Upper lobectomy }+ \\
\text { arterial patch }\end{array}$ & Alive 13 months \\
\hline 21 & 67 & Left & Squamous & IPV & 1 & Present & $\begin{array}{r}\text { Induction CRT + } \\
\text { definitive CRT }\end{array}$ & Alive 10 months \\
\hline 22 & 56 & Left & Large cell & LA & $1-3$ & Present & $\begin{array}{c}\text { Induction CRT + } \\
\text { definitive CRT }\end{array}$ & Alive 8 months \\
\hline
\end{tabular}

Computed tomography (CT) finding: 1 = contact between a pulmonary vessel and the tumoral mass for more than $3 \mathrm{~cm}$ or more than 90 degrees without a recognizable fat plane, as both; $2=$ distortion or indentation of the involved vessels; $3=$ obliteration of pulmonary vessel lumen.

Ao $=$ aorta $\quad$ CRT $=$ chemoradiotherapy $\quad$ FVP $=$ flexible videopericardioscopy $\quad$ IPV $=$ inferior pulmonary vein; $\quad$ LA $=$ left atrium; $\quad$ PA $=$ pulmonary artery; $\quad \mathrm{SPV}=$ superior pulmonary vein; $\quad \mathrm{SVC}=$ superior vena cava.

\section{Statistics}

Group descriptive statistics are presented as mean \pm SD. Owing to the limited sample size, unpaired data were compared by the Mann-Whitney test and frequencies by the two-tailed Fisher exact test.

\section{Results}

Eight right-sided and 14 left-sided procedures were performed. Mean operative time was $31 \pm 6$ minutes. No difference in operative time was found between right and left FVP (30 \pm 5 minutes versus $32 \pm 7$ minutes, respec- tively, $p=0.29$ ). No patient had severe pleural adhesions contraindicating video-assisted thoracoscopic surgery. Mean hospital stay was $2.9 \pm 1$ days for patients not undergoing thoracotomy and $6.3 \pm 1$ days for patients receiving FVP plus immediate resection. No procedurerelated mortality or morbidity were observed.

The outcome and most meaningful data of the study cohort are illustrated in Figure 3 and Table 1, respectively. Technical feasibility was satisfactory in 21 patients $(95.4 \%)$ and poor in 1 patient $(4.6 \%)$ owing to pericardial adhesions preventing exploration.

Among 21 patients in whom FVP was feasible, ana- 
tomic visualization was scored as diagnostic in 19 patients $(90.5 \%)$ and as nondiagnostic in $2(9.5 \%)$. In 7 patients $(33.3 \%)$, FVP downstaged local tumor extent, suggesting absent or minimal proximal vascular tumor spread. These findings were confirmed at thoracotomy, when radical resection was always accomplished. In these same patients, the existence of tumor-free vascular margins was furthermore confirmed by pathology examination. Definitive pathologic staging in these patients was pT3N1 in 2 patients, pT3N0 in 2 patients, pT2N0 in 3 patients, and pT2N1 in 1 patient. The FVP suggested the presence of an unresectable mass in 12 patients $(57.1 \%)$ due to intrapericardial vascular involvement (Table 1). In 3 of these patients $(14.3 \%)$, further unexpected findings were noticed such as pleural metastases, invasion of the aorta, and invasion of the superior vena cava in 1 patient each. No patient in this subgroup underwent thoracotomy. The resectability rate at FVP was higher for patients with nonsquamous tumors (8 of 15 patients, or $53.3 \%$, versus 0 of 7 patients, $p=0.022$ ), whereas there was no difference in resectability rate according to tumor side. A nondiagnostic finding was due to incomplete visualization of the the right pulmonary artery in 2 patients with bulky hilar tumors that prevented adequate visualization of the intrapericardial tract of the pulmonary artery. One of these patients underwent exploratory thoracotomy 7 days after initial FVP, and it demonstrated an unresectable lesion with extensive infiltration of the pulmonary artery and trachea; the other patient preferred to enter the neoadjuvant therapy arm.

Finally, in the subgroup undergoing resection after induction therapy, definitive staging was pT2N0 in 3 patients and PT3N0 in 1 patient.

\section{Comment}

In this study, FVP was easily performed in the majority of patients and allowed an increased resectability rate even though advanced radiologic clinical staging had suggested an unresectable disease due to proximal vascular invasion. The FVP did in fact allow predicting resectability in 7 patients, or $32 \%$ of the entire cohort. Such an increased resectability rate was subsequently confirmed at both thoracotomy and histology examination. On the other hand, FVP showed some limitations, providing nondiagnostic anatomic visualization in two instances.

Thus far, the question of evaluating proximal vascular involvement of NSCLC by minimally invasive staging procedures has been scarcely investigated. In 1999, Van Schil and coworkers [15] performed intrapericardial assessment of left-sided tumors through anterior mediastinotomy. In 2002, Loscertales and coworkers [13] reported an interesting series of 27 patients with centrally located tumors in whom pericardioscopy with exploration of proximal pulmonary vessels was accomplished using rigid instrumentation. Although we acknowledge the validity of the surgical technique proposed by Loscertales and coworkers [13], we believe that the use of a fiberoptic videobronchoscope could offer some advantages in terms of safety and effectiveness because of its small diameter and flexibility. In fact, exploration of the pericardial cavity by this instrument was easily accomplished in the majority of the patients with a low risk of vascular injury. Despite the limitation provided bilaterally by pericardial sinuses and by the Botallo's ligament on the left pulmonary artery, we have found that the videobronchoscope can easily slide around the vessel's wall, thus allowing visualization of areas such as the posterior aspects of the pulmonary vessels, which are difficult if not impossible to be visualized by a rigid scope. Video-assisted, magnified vision allowed an accurate assessment of tumor-free portions of pulmonary vessels, which were useful for eventual stapling.

So far, the main limitation of FVP relates, in our opinion, to the presence of bulky hilar masses, which can jeopardize transformation of the virtual pericardial cavity into a real explorable space. Indeed, this transformation is achieved by tailoring the extent of the pericardial opening and applying vertical traction on the pericardial walls, maneuvers that can be blocked because of the increased rigidity of the neoplastic mass. In these instances, visualization of the intrapericardial tract of right pulmonary artery, which is partially covered by the superior vena cava, can be hampered, as happened in 2 patients of our series. Further technical improvements such as the recently reported endosonography used during videopericardioscopy [16] will probably help overcome this limitation in the near future.

One of the expected goals of FVP was to reduce exploratory thoracotomies. In our study, FVP indicated the presence of an unresectable disease in 12 of 19 patients in whom the procedure was considered diagnostic. We believe this to represent a satisfactory outcome in terms of ethical and cost-versus-benefit concerns. Furthermore, although 2 patients still received exloratory thoracotomy owing to the failure of FVP to correctly assess proximal vascular involvement, it must be taken into account that all patients had been previously considered unresectable at multislice CT.

The role of exploratory thoracotomy in locally advanced NSCLC is still a matter of debate, as it is believed by some surgeons that definitive surgical decision can be oriented only by direct palpation and accurate dissection [17-19]. However, Roeslin and coworkers [19] have found a mortality rate of $4 \%$ after exploratory thoracotomy, which also correlated with a poorer survival in comparison with the outcome of identical-stage nonsurgical patients.

In our study, only patients in whom adequate tumorfree vascular margins were clearly identified at FVP underwent thoracotomy, to minimize the risk of incomplete resection, which is associated with significantly worse 5-year survival [2, 3]. Furthermore, Pitz and coworkers [4] reported that among 89 T4 patients, 13 of the 19 surgical deaths were of patients with proximal vessel involvement, which raises questions as to the risk-tobenefit ratio of surgical therapy for this delicate patient subgroup.

An aggressive treatment strategy for stage IIIB NSCLC can entail direct inclusion of the patient in an induction 
therapy protocol [20]. However, we believe that the use of invasive staging methods in these patients has a rationale and can be justified. In fact, induction therapy can increase subsequent surgical morbidity and can be associated with significant toxicity [21, 22]. Moreover, marginal surgical candidates not responding to this kind of therapy may become rapidly and definitively unresectable.

In this series, all enrolled patients underwent advanced radiologic staging by total body FDG-PET and multislice CT with multiplanar reconstruction. Multislice CT was expected to yield improved details of hostile anatomic areas (namely, the aortopulmonary window or the subcarinal region) by avoiding overlapping of neighboring structures and providing better estimation of the contact between tumor mass and mediastinal structures, regardless of their axis [14, 23-25]. Nonetheless, multislice CT scan showed a $60.0 \%$ positive predictive value in assessing tumor spread to proximal vessels. This result is similar to that reported in previous studies employing conventional CT [7-11], while it is somewhat worst than that reported in one study by thin-section electron-beam CT [26] in which accuracy, sensitivity, and specificity in evaluating invasion of the pulmonary artery were $75 \%$, $77.8 \%$, and $71.4 \%$, respectively. It is worth noting that, in this study, if one considers left-sided FVP only, negative predictive value was $100 \%$, which suggests a high accuracy in detecting resectable lesions in these patients.

As far as the usefulness of magnetic resonance imaging in this setting $[27,28]$ is concerned, several studies have failed to demonstrate a superiority of magnetic resonance imaging versus CT in terms of diagnostic accuracy and interobserver variability $[29,30]$. Other newly available endobronchial ultrasonographic procedures are being actively investigated as additional staging tools, although so far they have been mainly employed for assessment of nodal status.

\section{Limitations}

We acknowledge as an important limitation of the study the impossibility of assessing sensitivity and positive predictive value due to the lack of routine central biopsy and thoracotomy confirmation of FVP findings, which prevented us from calculating the false positive rate. Furthermore, the small sample size did not allow statistical analysis to test relationships existing between FVP results and patient- or tumor-related factors. Finally, FVP proved not feasible or gave uncertain anatomic visualization in a few instances, reducing its overall accuracy as a staging tool.

In conclusion, in this study, FVP proved safe and feasible for the majority of the patients. It allowed a better assessment of centrally located NSCLC with radiologic evidence of proximal vascular involvement, eventually resulting in increased resectability rate. Further investigation is warranted to confirm our findings and reduce the procedure-related limitations observed in our small cohort.
This study was carried out within the Research Fellowship Program "Tecnologie e Terapie Avanzate in Chirurgia," appointed by Tor Vergata University of Rome, Italy.

\section{References}

1. Mountain CF. Revision in the international staging system of lung cancer. Chest 1997;111:1710-7.

2. Osaki T, Sugio $K$, Hanagiri $T$, et al. Survival and prognostic factors of surgically resected T4 non-small cell lung cancer. Ann Thorac Surg 2003;75:1745-51.

3. Rami-Porta R, Navarro-Mateu M, Freixnet J, et al. Type of resection and prognosis in lung cancer. Experience of a multicentre study. Eur J Cardiothorac surg 2005;28:622-8.

4. Pitz CCM, Brutel de la Rivière $A$, van Swieten $H$, Westerman CJJ, Lammers JW, Van den Bosch JMM. Results of surgical treatment of T4 non-small cell lung cancer. Eur J Cardiothorac Surg 2003;24:1013-8.

5. DiPerna CA, Wood DE. Surgical management of T3 and T4 lung cancer. Clin Cancer Res 2005;11(Suppl):5038S-44S.

6. Grunenwald D, Andrè F, Le Pechoux C, et al. Benefit of surgery after chemoradiotherapy in stage IIIB (T4 and/or N3) non-small cell lung cancer. J Thorac Cardiovasc Surg 2001;122:796-802.

7. Herman SJ, Winton TL, Weisbrod GL, Towers MJ, Mentzer SJ. Mediastinal invasion by bronchogenic carcinoma: CT signs. Radiology 1994;190:841-6.

8. Glazer HS, Kaiser LR, Anderson DJ, et al. Indeterminate mediastinal invasion in bronchogenic carcinoma: CT evaluation. Radiology 1989;173:37-42.

9. Wursten HU, Vock P. Mediastinal infiltration of lung carcinoma (T4N0-1): the positive predictive value of computed tomography. Thorac Cardiovasc Surg 1987;35:355-60.

10. Izbicki JR, Thetter O, Karg O, Kreausser I, Passlick B, Trupka A. Accuracy of computed tomographic scan and surgical assessment for staging of bronchial carcinoma. J Thorac Cardiovasc Surg 1992;104:413-20.

11. Gdeedo A, Van Schil P, Corthouts B, Van Mieghem F, Van Meerbeeck J, Van Marck E. Comparison of imaging TNM [(i)TNM] and pathological TNM (pTNM) in staging of bronchogenic carcinoma. Eur J Cardiothorac Surg 1997;12:224-7.

12. Sebastian-Quetglas F, Molins L, Baldo X, Buitrago J, Vidal G. Clinical value of video-assisted thoracoscopy for preoperative staging of non-small cell lung cancer. Lung Cancer 2003;297-301.

13. Loscertales J, Jimenez-Merchan R, Congregado-Loscertales $\mathrm{M}$, et al. Usefulness of videothoracoscopic intrapericardial examination of pulmonary vessels to identify resectable clinical T4 lung cancer. Ann Thorac Surg 2002;73:1563-6.

14. Padhani AR, Fishman FK, Heitmiller RF, Wang KP, Wheeler $\mathrm{JH}, \mathrm{Kuhlman}$ JE. Multiplanar display of spiral CT data of the pulmonary hila in patients with lung cancer. Preliminary observations. Clin Imaging 1995;19:252-7.

15. Van Schil PE, Kneapen PJ, Brutel de la Rivière A, van Swieten HA, Vanderschueren RG. Extended use of diagnostic anterior mediastinotomy: intrapericardial exploration and evaluation of resectability of bronchogenic left-sided carcinoma. Eur J Cardiothorac Surg 1991;5:588-91.

16. Ohno K, Utsumi T, Sasaki Y, Suzuki Y. Videopericardioscopy using endothoracic sonography for lung cancer staging. Ann Thorac Surg 2005;79:1780-2.

17. Michaelson R, Shaughnessey E, Wagman LD, Grannis FW Jr. Lung cancer found unresectable at thoracotomy: reappraisal of an old problem. Ann Surg 1999;65:1023-6.

18. Bergeron P, Martelet JP, Casanova P, et al. Justification and benefits of exploratory thoracotomy in stage IIIb bronchopulmonary cancer. Ann Chirug 1990;44:622-9.

19. Roeslin N, Pallasse MC, Dumont P, Wihlm JM, Morand G, Witz JP. Outcome of 100 necessary exploratory thoracotomies for bronchial cancer. Ann Chirug 1990;44:670-2. 
20. Rendina EA, Venuta F, DeGiacomo $\mathrm{T}$, et al. Induction chemotherapy for T4 centrally located non-small cell lung cancer. J Thorac Cardiovasc Surg 1999;117:225-33.

21. Martin J, Ginsberg RJ, Abolhonda A, et al. Morbidity and mortality after neoadjuvant therapy for lung cancer: the risks of right pneumonectomy. Ann Thorac Surg 2001;72: 1149-54.

22. Roberts JR, Eustis C, Devore R, Carbone D, Choy H, Johnson D. Induction chemotherapy increases postoperative complications in patients undergoing resection for non-small cell lung cancer. Ann Thorac Surg 2001;72:885-8.

23. Quint LE, McShan DL, Glazer GM, Orringer MB, Francis IR, Gross BH. Three dimensional CT of central lung tumors. Clin Imaging 1990;14:323-9.

24. Filipek MS, Gosselin MD. Multidetector pulmonary CT angiography: advances in the evaluation of pulmonary artery disease. Semin Ultr CT MRI 2004;25:83-98.

25. Kawamoto S, Johnson PT, Fishman EK. Three-dimensional CT angiography of the thorax: clinical applications. Semin Ultr CT MRI 1998;19:425-38.
26. Takahashi M, Shimoyama K, Murata K, et al. Hilar and mediastinal invasion of bronchogenic carcinoma: evaluation by thin-section electron-beam computed tomography. J Thorac Imaging 1997;12:195-9.

27. Sans N, Giron J, Domenech B, et al. MRI in the study of the arterial ligament and the left pulmonary artery in the preoperative staging of left upper lobe bronchial cancers. J Radiol 1998;79:403-8.

28. Takahashi K, Furuse M, Hanaoka K, et al. Pulmonary vein and left atrial invasion by lung cancer: assessment by breath-hold gadolinium-enhanced three dimensional MR angiography. J Comput Assist Tomogr 2000;24:557-61.

29. Templeton PA, Caskey CI, Zerhouni EA. Current uses of CT and MR imaging in the staging of lung cancer. Radiol Clin North Am 1990;28:631-46.

30. Webb WR, Sarin M, Zerhouni EA, Heelan RT, Glazer GM, Gatsonis C. Interobserver variability in $\mathrm{CT}$ and $\mathrm{MR}$ staging of lung cancer. J Comput Assist Tomogr 1993;17: $841-6$.

\section{Requirements for Recertification/Maintenance of Certification in 2007}

Diplomates of the American Board of Thoracic Surgery who plan to participate in the Recertification/ Maintenance of Certification process in 2007 must hold an active medical license and must hold clinical privileges in thoracic surgery. In addition, a valid certificate is an absolute requirement for entrance into the recertification/maintenance of certification process. If your certificate has expired, the only pathway for renewal of a certificate is to take and pass the Part I (written) and the Part II (oral) certifying examinations.

The American Board of Thoracic Surgery will no longer publish the names of individuals who have not recertified in the American Board of Medical Specialties directories. The Diplomate's name will be published upon successful completion of the recertification/maintenance of certification process.

The CME requirements are 70 Category I credits earned during the 2 years prior to application. At least 35 CME hours need to be in thoracic surgery. Category II credits are not allowed. The Physicians Recognition Award for recertifying in general surgery is not allowed in fulfillment of the CME requirements. Interested individuals should refer to the Booklet of Information for a complete description of acceptable CME credits.

Diplomates should maintain a documented list of their major cases performed during the year prior to application for recertification. This practice review should consist of 1 year's consecutive major operative experiences.
If more than 100 cases occur in 1 year, only 100 should be listed.

Candidates for recertification/maintenance of certification will be required to complete all sections of the SESATS self-assessment examination. It is not necessary for candidates to purchase SESATS individually because it will be sent to candidates after their application has been approved.

Diplomates may recertify the year their certificate expires, or if they wish to do so, they may recertify up to two years before it expires. However, the new certificate will be dated 10 years from the date of expiration of their original certificate or most recent recertification certificate. In other words, recertifying early does not alter the 10 -year validation.

Recertification/maintenance of certification is also open to Diplomates with an unlimited certificate and will in no way affect the validity of their original certificate.

The deadline for submission of applications for the recertification/maintenance of certification process is May 10 each year. A brochure outlining the rules and requirements for recertification/maintenance of certification in thoracic surgery is available upon request from the American Board of Thoracic Surgery, 633 N St. Clair St, Suite 2320, Chicago, IL 60611; telephone: (312) 202-5900; fax: (312) 202-5960; e-mail: info@abts.org. This booklet is also published on the website: www.abts.org. 


\section{Flexible Videopericardioscopy in cT4 Nonsmall-Cell Lung Cancer With Radiologic Evidence of Proximal Vascular Invasion}

Eugenio Pompeo, Federico Tacconi and Tommaso C. Mineo

Ann Thorac Surg 2007;83:402-408

DOI: 10.1016/j.athoracsur.2006.09.031

\begin{tabular}{|c|c|}
\hline $\begin{array}{l}\text { Updated Information } \\
\& \text { Services }\end{array}$ & $\begin{array}{l}\text { including high-resolution figures, can be found at: } \\
\text { http://ats.ctsnetjournals.org/cgi/content/full/83/2/402 }\end{array}$ \\
\hline References & $\begin{array}{l}\text { This article cites } 29 \text { articles, } 14 \text { of which you can access for free at: } \\
\text { http://ats.ctsnetjournals.org/cgi/content/full/83/2/402\#BIBL }\end{array}$ \\
\hline Citations & $\begin{array}{l}\text { This article has been cited by } 1 \text { HighWire-hosted articles: } \\
\text { http://ats.ctsnetjournals.org/cgi/content/full/83/2/402\#otherarticles }\end{array}$ \\
\hline Subspecialty Collections & $\begin{array}{l}\text { This article, along with others on similar topics, appears in the } \\
\text { following collection(s): } \\
\text { Lung - cancer } \\
\text { http://ats.ctsnetjournals.org/cgi/collection/lung_cancer }\end{array}$ \\
\hline Permissions \& Licensing & $\begin{array}{l}\text { Requests about reproducing this article in parts (figures, tables) or } \\
\text { in its entirety should be submitted to: } \\
\text { http://www.us.elsevierhealth.com/Licensing/permissions.jsp or } \\
\text { email: healthpermissions@elsevier.com. }\end{array}$ \\
\hline Reprints & $\begin{array}{l}\text { For information about ordering reprints, please email: } \\
\text { reprints@elsevier.com }\end{array}$ \\
\hline
\end{tabular}

